\title{
Uric Acid and Prevalence of Hypertension in a General Population of Japanese: ISSA-CKD Study
}

\author{
Ikuko Miyabayashia $^{\mathrm{a}}$, Shigetomo Mori ${ }^{\mathrm{b}}$, Atsushi Satoh ${ }^{\mathrm{b}}$, Miki Kawazoe ${ }^{\mathrm{b}}$, Shunsuke Funakoshi ${ }^{\mathrm{b}}$, \\ Shintaro Ishida ${ }^{\mathrm{c}}$, Toshiki Maeda ${ }^{\mathrm{b}}$, Chikara Yoshimura ${ }^{\mathrm{b}}$, Kazuhiro Tada ${ }^{\mathrm{d}}$, Koji Takahashid, \\ Kenji Ito ${ }^{d}$, Tetsuhiko Yasuno ${ }^{d}$, Kosuke Masutanid ${ }^{d}$, Seiji Kondo ${ }^{c}$, \\ Hitoshi Nakashima ${ }^{\mathrm{d}}$, Hisatomi Arima ${ }^{\mathrm{b}, \mathrm{e}}$
}

\begin{abstract}
Background: There is uncertainty surrounding the causal relationship between serum uric acid and hypertension. The aim was to investigate the association between serum uric acid and prevalence of hypertension in a general population of Japanese.

Methods: This was a population-based cross-sectional study using health check-up data of the residents of the Iki City, Nagasaki Prefecture, Japan. A total of 7,484 participants aged 30 years or older were included in this study. Serum uric acid was classified into four groups: group $1(<357 \mu \mathrm{mol} / \mathrm{L}(<6 \mathrm{mg} / \mathrm{dL}))$, group $2(357-415$ $\mu \mathrm{mol} / \mathrm{L}(6-6.9 \mathrm{mg} / \mathrm{dL}))$, group $3(416$ - $475 \mu \mathrm{mol} / \mathrm{L}(7-7.9 \mathrm{mg} / \mathrm{dL}))$ and group $4(\geq 476 \mu \mathrm{mol} / \mathrm{L}(\geq 8 \mathrm{mg} / \mathrm{dL}))$. Hypertension was defined as blood pressure (BP) levels of $\geq 140 / 90 \mathrm{~mm} \mathrm{Hg}$ or use of BP lowering medications.

Results: Hypertension was observed among 3,467 participants (prevalence $46.3 \%$ ). The prevalence of hypertension increased with elevation of serum uric acid levels: $42.8 \%$ in group $1,55.0 \%$ in group 2, $57.6 \%$ in group 3 and $59.8 \%$ in group 4 ( $\mathrm{P}<0.001$ for trend). This association was significant even after adjustment for other risk factors including age, sex, current smoking, current alcohol intake, obesity, diabetes, dyslipidemia, estimated glomerular filtration rate and proteinuria: odds ratios (95\% confidence intervals) were 1.50 (1.28 - 1.77) for group 2, 1.58 (1.25 - 1.99) for group 3 and 1.89 (1.36 2.64) for group 4 compared with the reference group of group $1(\mathrm{P}<$ 0.001 for trend).
\end{abstract}

Manuscript submitted April 18, 2020, accepted June 4, 2020

Published online June 25, 2020

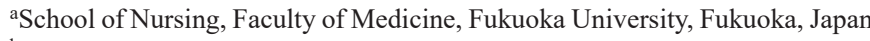
bDepartment of Preventive Medicine and Public Health, Faculty of Medicine, Fukuoka University, Fukuoka, Japan

'Department of Oral and Maxillofacial Surgery, Faculty of Medicine, Fukuoka University, Fukuoka, Japan

${ }^{\mathrm{d}}$ Division of Nephrology and Rheumatology, Department of Internal Medicine, Faculty of Medicine, Fukuoka University, Fukuoka, Japan

${ }^{\mathrm{e}}$ Corresponding Author: Hisatomi Arima, Department of Preventive Medicine and Public Health, Faculty of Medicine, Fukuoka University, 7-45-1 Nanakuma, Jonan-ku, Fukuoka 814-0180, Japan. Email: harima@fukuoka-u.ac.jp

doi: https://doi.org/10.14740/jocmr4171
Conclusions: Serum uric acid was clearly associated with prevalence of hypertension in a general population of Japanese.

Keywords: Serum uric acid; Hypertension, Japanese

\section{Introduction}

Cardiovascular disease is one of the leading causes of premature death [1]. High blood pressure (BP) is one of the most important modifiable risk factors of cardiovascular disease and approximately a half of fatal cardiovascular events are estimated to be attributable to hypertension [2]. In Japan, average BP levels have declined during the past few decades (probably due to improvement in treatment and control of hypertension), while prevalence rates of hypertension have remained stable [3]. Effective prevention of hypertension and subsequent cardiovascular events will require strategies based on up-to-date knowledge on risk factors of hypertension.

A number of observational studies reported the association between serum uric acid and hypertension in a variety of populations, while no clear associations were reported from other observational or Mendelian randomization studies [4, 5]. As a result, uncertainty remains surrounding the causal relationship between serum uric acid and hypertension. The aim of this study was to investigate the association between serum uric acid and prevalence of hypertension in a general population of Japanese.

\section{Materials and Methods}

\section{Study design and participants}

The Iki Epidemiological Study of Atherosclerosis and Chronic Kidney Disease (ISSA-CKD) is a population-based observational study of the residents of the Iki City, Nagasaki Prefecture, Japan. Details of the ISSA-CKD study have been described previously $[6,7]$. In brief, a total of 7,895 residents aged 30 years or older underwent annual health check-ups conducted by the local government of the Iki City between 
2008 and 2017. After exclusion of 411 residents with missing information on age, sex, serum uric acid, BP or use of BP lowering medication, a total of 7,484 participants were included in the present analysis. This study was conducted in compliance with the Ethical Guidelines for Medical and Health Research Involving Human Subjects of Japan as well as with the Helsinki Declaration, and was approved by the Fukuoka University Clinical Research \& Ethics Centre (No. 2017M010).

\section{Data collection}

Information on smoking habits and alcohol intake was obtained using a standard questionnaire. Current smoking was defined as participants who had smoked 100 cigarettes or more, or who had smoked regularly for more than 6 months. Alcohol intake was classified into current daily drinking or not. Height and weight were measured with the participant wearing light clothes without shoes, and body mass index (BMI, $\mathrm{kg} / \mathrm{m}^{2}$ ) was calculated. Obesity was defined as BMI $\geq 25 \mathrm{~kg} / \mathrm{m}^{2}$. BP was measured by trained staff in the right upper arm using mercury, automated, or aneroid sphygmomanometers with appropriately sized cuffs, after at least 5 min of rest in a sitting position, in accordance with standardized guidelines [8]. BP was measured twice and the mean of the two values was used in the present analysis. Casual blood and urine samples were collected. Serum uric acid was determined using the enzyme method and classified into four groups: group $1(<357 \mu \mathrm{mol} / \mathrm{L}(<6 \mathrm{mg} /$ $\mathrm{dL})$ ), group $2(357-415 \mu \mathrm{mol} / \mathrm{L}(6-6.9 \mathrm{mg} / \mathrm{dL}))$, group 3 (416 - $475 \mu \mathrm{mol} / \mathrm{L}(7-7.9 \mathrm{mg} / \mathrm{dL}))$ and group $4(\geq 476 \mu \mathrm{mol} / \mathrm{L}(\geq 8$ $\mathrm{mg} / \mathrm{dL})$ ). Plasma glucose concentration was determined using the enzyme method and glycated hemoglobin (HbAlc) level (NGSP value) was determined using the high-performance liquid chromatography method. Presence of diabetes was defined as fasting glucose concentration $\geq 7.0 \mathrm{mmol} / \mathrm{L}$, non-fasting glucose concentration $\geq 11.1 \mathrm{mmol} / \mathrm{L}, \mathrm{HbAlc} \geq 6.5 \%$, or use of glucose lowering therapy. Serum low-density lipoprotein (LDL) cholesterol, high-density lipoprotein (HDL) cholesterol and triglyceride levels were determined enzymatically. Dyslipidemia was defined by LDL cholesterol $\geq 3.62 \mathrm{mmol} / \mathrm{L}$, HDL cholesterol $<1.03 \mathrm{mmol} / \mathrm{L}$, triglycerides $\geq 1.69 \mathrm{mmol} / \mathrm{L}$, or use of lipid lowering medications. Serum creatinine concentration was determined using an enzymatic method and estimated glomerular filtration rate (eGFR) was estimated using the formula of the Japanese Society of Nephrology, as follows: eGFR $\left(\mathrm{mL} / \mathrm{min} / 1.73 \mathrm{~m}^{2}\right)=194 \times$ serum creatinine $(\mathrm{mg} / \mathrm{dL})^{-1.094} \times$ $\operatorname{age}^{-0.287}(\times 0.739$ if female $)$ [9]. Urinary protein concentration was evaluated using dipsticks, and $(1+)$ or higher score was regarded as the presence of proteinuria. Chronic kidney disease (CKD) was defined as eGFR $<60 \mathrm{~mL} / \mathrm{min} / 1.73 \mathrm{~m}^{2}$ and/or presence of proteinuria.

\section{Definition of hypertension}

Hypertension was defined as BP levels of $\geq 140 / 90 \mathrm{~mm} \mathrm{Hg}$ or use of BP lowering medications.

\section{Statistical analysis}

Continuous variables were expressed as mean (standard deviation (SD)) and compared using analysis of variance. Categorial variables were expressed as number of participants (percentage) and compared using Chi-squared tests. Crude and multivariable-adjusted odds ratios (ORs) and their $95 \%$ confidence intervals $(95 \%$ CIs) were estimated using logistic regression models. A two-tailed $\mathrm{P}$ value of less than 0.05 was considered statistically significant. Analyses were carried out using the SAS version 9.4.

\section{Results}

Table 1 shows the characteristics according to groups defined by serum uric acid levels. Participants with higher serum uric acid levels were more likely to be male, current smokers, current drinkers and obese, and were more likely to have dyslipidemia and CKD.

Hypertension was observed among 3,467 participants (prevalence $46.3 \%$ ). The prevalence of hypertension increased with elevation of serum uric acid levels: $42.8 \%$ in group 1, $55.0 \%$ in group $2,57.6 \%$ in group 3 and $59.8 \%$ in group 4 $(\mathrm{P}<0.001$ for trend) (Table 2). This association was significant even after adjustment for other risk factors including age, sex, current smoking, current alcohol intake, obesity, diabetes, dyslipidemia, eGFR and proteinuria: ORs $(95 \% \mathrm{CI})$ were 1.50 $(1.28$ - 1.77) for group 2, $1.58(1.25$ - 1.99) for group 3 and 1.89 (1.36 - 2.64) for group 4 compared with the reference group of group $1(\mathrm{P}<0.001$ for trend) (Table 2). Multivariable-adjusted OR $(95 \% \mathrm{CI})$ per $1 \mathrm{SD}(93 \mu \mathrm{mol} / \mathrm{L}(1.57 \mathrm{mg} / \mathrm{dL}))$ increase in serum uric acid was $1.32(1.22-1.43)(\mathrm{P}<0.001)$. There were comparable ORs for prevalent hypertension per 1 SD increase of serum uric acid between subgroups defined by gender (OR 1.26 (95\% CI 1.14 - 1.40) for male and 1.39 (1.23 - 1.58) for female, $\mathrm{P}=0.235$ for interaction), current alcohol intake (OR 1.39 (95\% CI 1.26 - 1.53) for no current alcohol intake and $1.19(1.03-1.37)$ for current alcohol intake, $\mathrm{P}=$ 0.125 for interaction) or presence of CKD (OR 1.32 (95\% CI $1.21-1.43)$ for no CKD and $1.16(1.01-1.33)$ for $\mathrm{CKD}, \mathrm{P}=$ 0.847 for interaction) (Table 3 ).

\section{Discussion}

There was a positive association between serum uric acid and prevalence of hypertension in the present large-scale crosssectional study of general Japanese. These associations remained significant after adjustment for the effects of confounding factors such as age, sex, current smoking, current alcohol intake, obesity, diabetes, dyslipidemia, eGFR and proteinuria. Comparable associations between serum uric acid and prevalence of hypertension were also observed between subgroups defined by gender, daily alcohol intake and presence of CKD.

Many observational studies reported the association between serum uric acid and hypertension [10-14]. However, current evidence is mainly derived from Western popula- 
Table 1. Baseline Characteristics According to Serum Uric Acid Levels

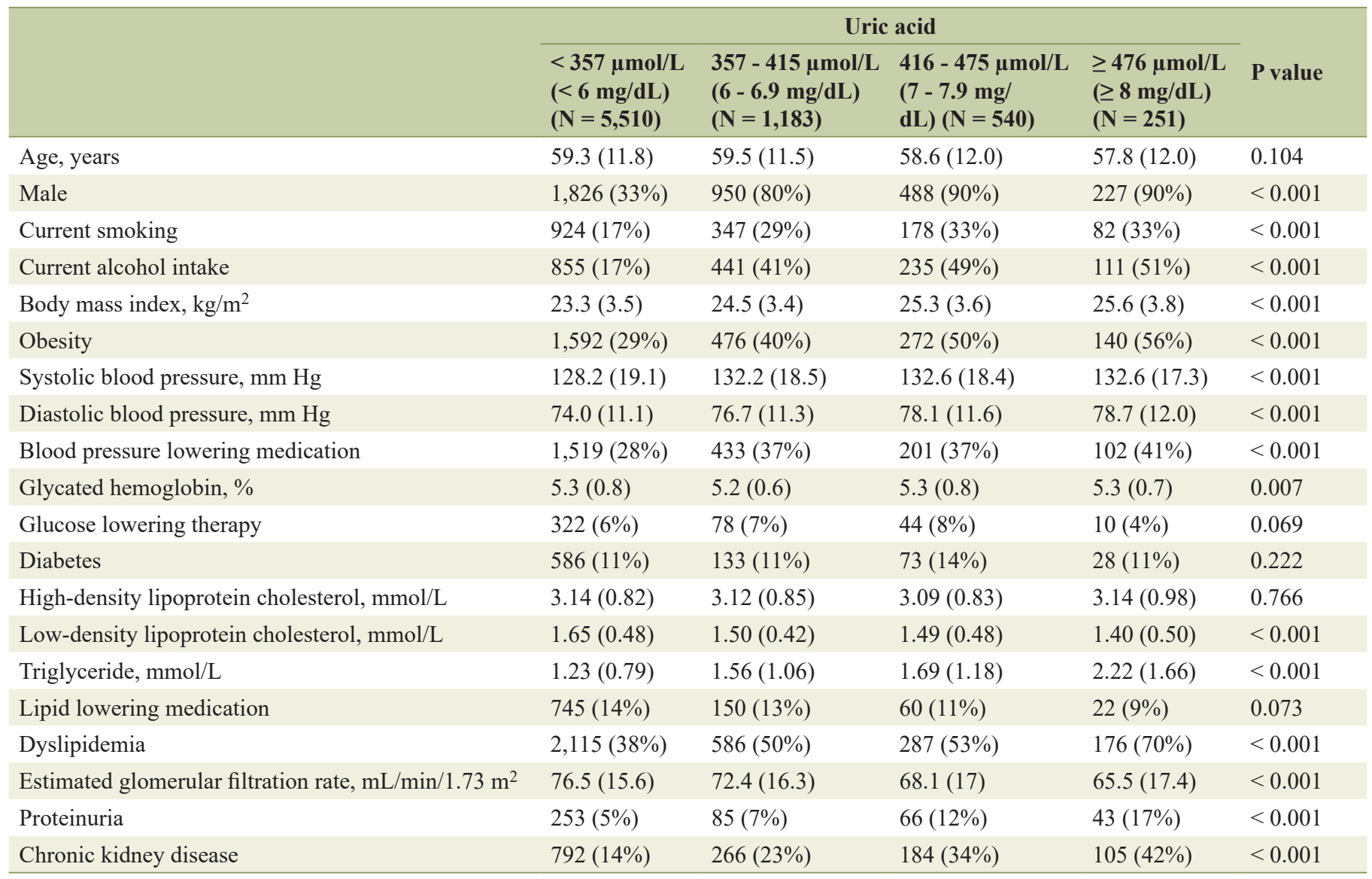

Values are mean (standard deviation), or number of participants (percent).

tions. In contrast, a few epidemiological studies reported the association between hyperuricemia and hypertension among Japanese. The Osaka Health Study reported increased risks of incident hypertension associated with elevation of serum uric acid levels among 6,356 Japanese men aged 35 - 60 years [15]. Nakanishi et al also reported similar associations between serum uric acid levels and incidence of hypertension among 2,310 Japanese male office workers aged 35 - 59 years [16]. Nagahama et al reported 1.57-fold higher risks of incident hypertension in participants with hyperuricemia $(416 \mu \mathrm{mol} / \mathrm{L}$ (7 $\mathrm{mg} / \mathrm{dL})$ in men or $\geq 357 \mu \mathrm{mol} / \mathrm{L}(6 \mathrm{mg} / \mathrm{dL})$ in women $)$ among
4,489 Japanese men and women [17]. The present study of 7,484 general Japanese confirmed the findings from the previous studies and demonstrated that there was a linear association between serum uric acid and prevalence of hypertension from serum uric acid level of $\geq 357 \mu \mathrm{mol} / \mathrm{L}(6 \mathrm{mg} / \mathrm{dL})$ in a general population of Japanese.

Emerging evidence suggests a pathogenic role of hyperuricemia in development of CKD [18]. Because CKD is a strong determinant of hypertension, the link between serum uric acid and hypertension might in part be mediated by CKD. However, most prior studies [10, 12-17] (including studies

Table 2. Association of Serum Uric Acid and Prevalence of Hypertension

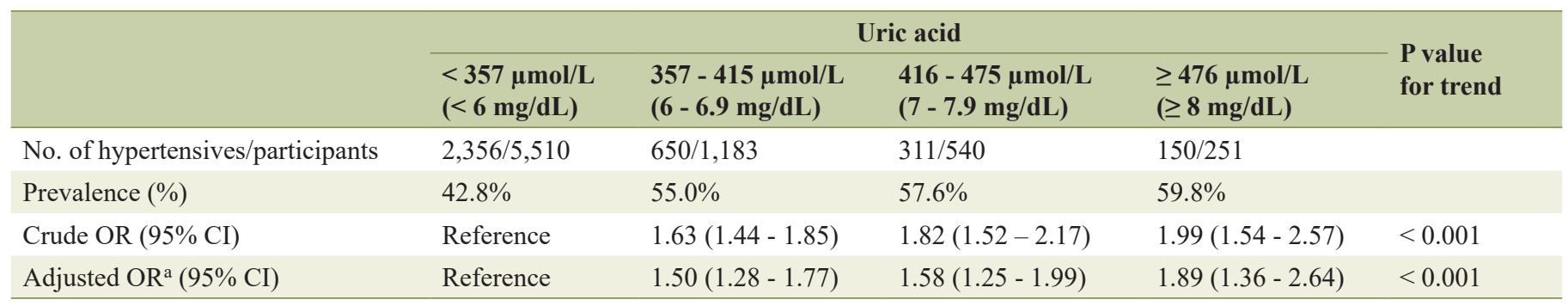

aAdjusted for age, sex, current smoking, current alcohol intake, obesity, diabetes, dyslipidemia, estimated glomerular filtration rate and proteinuria. OR: odds ratio; Cl: confidence interval. 
Table 3. Association of Serum Uric Acid and Prevalence of Hypertension in Subgroups

\begin{tabular}{llc}
\hline Subgroup & Adjusted odds ratio per $\mathbf{1}$ SD $^{\mathrm{a}}$ increase in serum uric acid $\mathbf{( 9 5 \%}$ CI) & P value for interaction \\
\hline $\begin{array}{l}\text { Gender } \\
\quad \text { Male }\end{array}$ & $1.26(1.14-1.40)^{\mathrm{b}}$ & 0.235 \\
$\quad$ Female & $1.39(1.23-1.58)^{\mathrm{b}}$ & 0.125 \\
Current alcohol intake & $1.39(1.26-1.53)^{\mathrm{c}}$ & \\
$\quad$ No & $1.19(1.03-1.37)^{\mathrm{c}}$ & 0.847 \\
$\quad$ Yes & $1.32(1.21-1.43)^{\mathrm{d}}$ & \\
Chronic kidney disease & $1.16(1.01-1.33)^{\mathrm{d}}$ \\
$\quad$ Absent & Present &
\end{tabular}

a93 $\mu \mathrm{mol} / \mathrm{L}$ (1.57 mg/dL). ${ }^{b}$ Adjusted for age, current smoking, current alcohol intake, obesity, diabetes, dyslipidemia, estimated glomerular filtration rate and proteinuria. ${ }^{\mathrm{C} A d j u s t e d}$ for age, sex, current smoking, obesity, diabetes, dyslipidemia, estimated glomerular filtration rate and proteinuria. ${ }^{\mathrm{d}}$ Adjusted for age, sex, current smoking, current alcohol intake, obesity, diabetes and dyslipidemia. SD: standard deviation; Cl: confidence interval.

conducted in Japan [15-17]) did not control for the effects for eGFR or proteinuria in multivariable analyses. In this context, the Framingham study demonstrated significant effects of hyperuricemia on incidence of hypertension, independent of eGFR and proteinuria [11]. The present analysis confirmed the findings of the Framingham study and clearly demonstrated the association between serum uric acid and hypertension independent of eGFR and proteinuria. There were also no clear differences in associations between serum uric acid and prevalence of hypertension irrespective of presence of CKD. Based on the findings above, there seems to be limited role of CKD as a mediator of the link between hyperuricemia and hypertension.

The potential mechanisms underlying the relationship between serum uric and hypertension involve reduction of endothelial nitric oxide, activation of renin-angiotensin system (RAS) [19, 20], and renal microvascular diseases due to smooth muscle cell proliferation, inflammation and activation of local RAS [21].

Although this was a large-scale study of a general Japanese population, it has several limitations. First, because of the nature of a cross-sectional design, causal relationship was not clearly defined. Second, findings of this study may be affected by selection bias because participants who attended the health check-ups were more likely to be aware of healthy behaviors. Third, information on use of drugs for hyperuricemia and that on use of different types of BP lowering medications was not available in this study.

\section{Conclusions}

Serum uric acid was clearly associated with prevalence of hypertension in a general population of Japanese.

\section{Acknowledgments}

We appreciate residents and the local government of the Iki City, Nagasaki, Japan.

\section{Financial Disclosure}

This study was supported by research grants from the Iki City.

\section{Conflict of Interest}

HA received research grants from Daiichi Sankyo and Takeda, lecture fees from Bayer, Daiichi Sankyo, Fukuda Denshi, MSD, Takeda, Teijin and fees for consultancy from Kyowa Kirin outside of the submitted work. There is no other conflict of interest.

\section{Informed Consent}

Consent of participants was obtained using opt-out approach.

\section{Author Contributions}

$\mathrm{HN}$ and HA obtained data and funding, IM, SM, AS and HA conducted statistical analysis, IM and HA drafted the paper and all authors made critical review of the manuscript.

\section{Data Availability}

The authors declare that data supporting the findings of this study are available within the article.

\section{References}

1. GBD 2017 Disease and Injury Incidence and Prevalence Collaborators. Global, regional, and national incidence, prevalence, and years lived with disability for 354 diseases and injuries for 195 countries and territories, 19902017: a systematic analysis for the Global Burden of Dis- 
ease Study 2017. Lancet. 2018;392(10159):1789-1858.

2. O'Donnell MJ, Chin SL, Rangarajan S, Xavier D, Liu L, Zhang H, Rao-Melacini P, et al. Global and regional effects of potentially modifiable risk factors associated with acute stroke in 32 countries (INTERSTROKE): a casecontrol study. Lancet. 2016;388(10046):761-775.

3. Umemura S, Arima H, Arima S, Asayama K, Dohi Y, Hirooka Y, Horio T, et al. The Japanese society of hypertension guidelines for the management of hypertension (JSH 2019). Hypertens Res. 2019;42(9):1235-1481.

4. Wang J, Qin T, Chen J, Li Y, Wang L, Huang H, Li J. Hyperuricemia and risk of incident hypertension: a systematic review and meta-analysis of observational studies. PLoS One. 2014;9(12):e114259.

5. Li X, Meng X, Timofeeva M, Tzoulaki I, Tsilidis KK, Ioannidis JP, Campbell H, et al. Serum uric acid levels and multiple health outcomes: umbrella review of evidence from observational studies, randomised controlled trials, and Mendelian randomisation studies. BMJ. 2017;357:j2376.

6. Maeda T, Yoshimura C, Takahashi K, Ito K, Yasuno T, Abe Y, Masutani K, et al. Usefulness of the blood pressure classification in the new 2017 ACC/AHA hypertension guidelines for the prediction of new-onset chronic kidney disease. J Hum Hypertens. 2019;33(12):873-878.

7. Yasuno T, Maeda T, Tada K, Takahashi K, Ito K, Abe Y, Mukoubara S, et al. Effects of HbA1c on the development and progression of chronic kidney disease in elderly and middle-aged Japanese: Iki epidemiological study of atherosclerosis and chronic kidney disease (ISSA-CKD). Intern Med. 2020;59(2):175-180.

8. The Japanese Society of Cardiovascular Disease Prevention. Handbook for cardiovascular prevention. Tokyo: Hokendojinsha; 2014.

9. Matsuo S, Imai E, Horio M, Yasuda Y, Tomita K, Nitta $\mathrm{K}$, Yamagata $\mathrm{K}$, et al. Revised equations for estimated GFR from serum creatinine in Japan. Am J Kidney Dis. 2009;53(6):982-992.

10. Dyer AR, Liu K, Walsh M, Kiefe C, Jacobs DR, Jr., Bild DE. Ten-year incidence of elevated blood pressure and its predictors: the CARDIA study. Coronary Artery Risk Development in (Young) Adults. J Hum Hypertens. 1999;13(1):13-21.

11. Sundstrom J, Sullivan L, D'Agostino RB, Levy D, Kannel WB, Vasan RS. Relations of serum uric acid to longitudi- nal blood pressure tracking and hypertension incidence. Hypertension. 2005;45(1):28-33.

12. Mellen PB, Bleyer AJ, Erlinger TP, Evans GW, Nieto FJ, Wagenknecht LE, Wofford MR, et al. Serum uric acid predicts incident hypertension in a biethnic cohort: the atherosclerosis risk in communities study. Hypertension. 2006;48(6): 1037-1042.

13. Krishnan E, Kwoh CK, Schumacher HR, Kuller L. Hyperuricemia and incidence of hypertension among men without metabolic syndrome. Hypertension. 2007;49(2):298303.

14. Zhang W, Sun K, Yang Y, Zhang H, Hu FB, Hui R. Plasma uric acid and hypertension in a Chinese community: prospective study and metaanalysis. Clin Chem. 2009;55(11):2026-2034.

15. Taniguchi Y, Hayashi T, Tsumura K, Endo G, Fujii S, Okada K. Serum uric acid and the risk for hypertension and Type 2 diabetes in Japanese men: The Osaka Health Survey. J Hypertens. 2001;19(7):1209-1215.

16. Nakanishi N, Okamoto M, Yoshida H, Matsuo Y, Suzuki K, Tatara K. Serum uric acid and risk for development of hypertension and impaired fasting glucose or Type II diabetes in Japanese male office workers. Eur J Epidemiol. 2003;18(6):523-530.

17. Nagahama K, Inoue T, Iseki K, Touma T, Kinjo K, Ohya Y, Takishita S. Hyperuricemia as a predictor of hypertension in a screened cohort in Okinawa, Japan. Hypertens Res. 2004;27(11):835-841.

18. Zhu P, Liu Y, Han L, Xu G, Ran JM. Serum uric acid is associated with incident chronic kidney disease in middleaged populations: a meta-analysis of 15 cohort studies. PLoS One. 2014;9(6):e100801.

19. Mazzali M, Hughes J, Kim YG, Jefferson JA, Kang DH, Gordon KL, Lan HY, et al. Elevated uric acid increases blood pressure in the rat by a novel crystal-independent mechanism. Hypertension. 2001;38(5):1101-1106.

20. Sanchez-Lozada LG, Tapia E, Santamaria J, Avila-Casado C, Soto V, Nepomuceno T, Rodriguez-Iturbe B, et al. Mild hyperuricemia induces vasoconstriction and maintains glomerular hypertension in normal and remnant kidney rats. Kidney Int. 2005;67(1):237-247.

21. Watanabe S, Kang DH, Feng L, Nakagawa T, Kanellis J, Lan H, Mazzali M, et al. Uric acid, hominoid evolution, and the pathogenesis of salt-sensitivity. Hypertension. 2002;40(3):355-360. 